\title{
Elegância e atitude: diferenças sociais e de gênero no mundo da moda*
}

\begin{abstract}
Alexandre Bergamo**
Resumo

As distinções mais óbvias que podem ser observadas no mercado de moda são aquelas que dizem respeito às diferenças de gênero, independente da classe ou do grupo social a que se faça referência. Dentro desse universo podem ser encontradas duas noções, elegância e atitude, que condensam, a um só tempo, marcas de gênero, sociais e individuais. No caso da noção de elegância, o discurso, tanto quanto a roupa ou o próprio indivíduo, traduz sempre um ato de remissão a uma determinada concepção de ordem social, entendida como natural. As diferenças de gênero são relevantes, nesse contexto, porque demarcam posições sociais entendidas como naturais. Já a noção de atitude não cobra, necessariamente, uma ordem social $e$ natural, mas uma ordem pessoal. $\mathrm{O}$ discurso e a roupa traduzem um caráter individualista, supondo ser o indivíduo quem imprime um sentido a sua inserção social, ainda que eventual ou momentânea. Nesse contexto, na maior parte das vezes, o individualismo ganha expressão através de uma linguagem estruturada como se não tivesse gênero.
\end{abstract}

Palauras-chave: Moda, Gênero, Distinção Social, Representação da Realidade.

\footnotetext{
* Recebido para publicação em janeiro de 2004, aceito em abril de 2004.

** Unesp, Marília-São Paulo. bergamo@marilia.unesp.br
} 
Elegância $e$ atitude

Elegance and Attitude:

Social and Gender Differences in the Fashion World

\begin{abstract}
The most evident distinctions that can be seen in the fashion market are those related to gender differences, independently from the social class or group. In such universe, the notions of elegance and attitude can be found, and they condense simultaneously gender, social and individual marks. In the case of the notion of elegance, the discourse, as well as the clothes or the individual $\mathrm{him} / \mathrm{h}$ erself, always refers to a certain conception of the social order conceived as natural. Gender differences are relevant in this context because they indicate social positions understood as natural ones. Otherwise, the notion of attitude does not necessarily demand a social and natural order, but an individual one. Discourse and clothes reveal an individualistic aspect, assuming that it is the individual who produces meaning in his/her social insertion, even if only temporarily. In this context, most of the time, individualism is expressed in a genderless language.
\end{abstract}

Key Words: Fashion, Gender, Social Distinction, Representation of Reality. 
Até que ponto as diferenças de gênero são cruciais para a definição de papéis tanto na produção quanto no consumo de moda?

Quando se observam os desfiles de moda, tem-se um universo dividido em gêneros, masculino $e$ feminino, sendo que alguns estilistas chegam a se especializar ou a serem reconhecidos através de roupas feitas principalmente para homens ou para mulheres. Além da moda infantil, é claro, esta também dividida em gêneros. Assim como os desfiles, os manuais de moda recentemente publicados no Brasil também são dirigidos para homens ${ }^{1}$ ou para mulheres. ${ }^{2}$ Mas antes mesmo desses manuais serem publicados, essa divisão podia ser encontrada nas diversas revistas, femininas ou masculinas, com editoriais de moda dirigidos exclusivamente para homens ou mulheres ${ }^{3}$, ou então através de diferentes editoriais numa mesma revista. Obviamente os editoriais de moda não se restringem a essa classificação, há aqueles que apresentam roupas tanto para homens quanto para mulheres. ${ }^{4}$ As distinções mais óbvias que podem ser observadas no mercado de moda são, portanto, aquelas que dizem respeito às diferenças de gênero, independente da classe ou do grupo social a que se faça referência. $\mathrm{O}$ fato de que essas diferenças possam ser observadas desde os desfiles até as publicações especializadas no

1 Cf. os manuais de BARROS, Fernando de. Elegância: como o homem deve se vestir. São Paulo, Negócio, 1997; e de KAliL. Glória. Chic Homem: manual de moda e estilo. São Paulo, Senac, 1998.

2 Cf. os manuais de KALIL, Glória. Chic: um guia básico de moda e estilo. São Paulo, Senac, 1997; de JoffILY, Ruth. Vista-se como você é: um guia de moda para mulheres de todos os tipos. Porto Alegre, L\&PM, 1997; e de PASCOLATO, Constanza. Essencial: o que você precisa saber para viver com mais estilo. Rio de Janeiro, Objetiva, 1998.

3 Como são, apenas para citar os exemplos mais conhecidos do mercado editorial nacional, as revistas Cláudia e Playboy, ambas publicadas pela editora Abril e com editoriais de moda dirigidos para mulheres, no primeiro caso, e homens, no segundo.

4 É o caso de revistas dirigidas a grupos específicos, como, por exemplo, a Raça, publicada pela editora Símbolo e que visa o público negro. 
Elegância $e$ atitude

assunto sugere que o mecanismo de significação da moda reside, basicamente, numa distinção de caráter universal e inquestionável entre gêneros. Outras distinções podem ser observadas, principalmente aquelas envolvendo diferenças de poder aquisitivo, mas nenhuma tem esse suposto caráter universal, que surge independente da classe social ou da idade.

Mas talvez o quadro não seja tão simples assim. O mercado de moda é expressivo de uma lógica muito mais complexa de distinção social e espaço possível para a atualização ou mesmo mudança dessa lógica. Não significa que as diferenças de gênero não existam. Obviamente elas existem e são facilmente observáveis, mas seu valor ou seu peso relativo precisa ser compreendido dentro da dinâmica própria que a moda expressa $e$ constitui. ${ }^{5}$

Dentro desse universo podem ser encontradas duas noções, elegância e atitude, que condensam, a um só tempo, marcas de gênero, sociais e individuais. O simples fato de que tais marcas apareçam condensadas é indicativo de quão inútil pode ser uma análise que tome qualquer uma delas como referência única ou universal. Além disso, há outras complicações analíticas. Assim como tais marcas podem aparecer condensadas, elas podem, também, aparecer dissociadas. Ou seja, em diversos momentos as noções de elegância e de atitude expressam distinções sociais ou individuais sem que as diferenças de gênero tenham, necessariamente, qualquer relevância. Para completar o quadro, elas tanto podem ser compreendidas como complementares quanto como opostas, a depender do contexto social em que são utilizadas. Os usos desses termos e os significados que podem adquirir a partir dos contextos em que são utilizados revelam,

${ }^{5}$ Ver, nesse sentido, o trabalho de Mello E SouzA, Gilda de. O Espírito das Roupas. São Paulo, Companhia das Letras, 1987. Ver também, embora não centrado na questão do gênero, mas na questão dos conflitos sociais e das relações de poder, o artigo de BOURDIEU, Pierre e DELSAUT, Yvette. Le couturier et sa griffe: contribuition à une théorie de la magie. Actes de la Recherche em Sciences Sociales, $\mathrm{n}^{\circ}$ 1, Paris, janeiro de 1975, pp.7-36. 
portanto, uma intensa rede de relações sociais, onde posições e distinções sociais são constantemente atualizadas.

Elegância, atitude, personalidade e estilo são termos muitas vezes utilizados como sinônimos no mundo da moda, mas não é incomum que possam ser encontrados expressando idéias completamente opostas. O fato é que nenhum desses termos possui um sentido unívoco. Contudo, não se trata de um caso de polissemia. Mais do que expressar significados distintos, esses termos expressam concepções de mundo, expressam a forma como o indivíduo concebe sua própria inserção no mundo. E, nesse sentido, eles traduzem a forma como determinados conflitos sociais são sentidos e, ao mesmo tempo, resolvidos.

\section{Elegância}

Mais do que qualquer moda, ela segue um estilo, sem perder as referências contemporâneas, é claro. Valoriza a qualidade, investe na discrição, não perde a pose em qualquer situação. (...) Qualidade é o que ela procura. E acha. Não importa onde: Paris, Nova York, Milão. Seu charme está muito mais no estilo do que na surpreendente combinação de peças. Discreta, parece que a Clássica anda num pedestal. E pode ter certeza: não cairá jamais! ${ }^{6}$

O texto acima, escrito por uma importante consultora $e$ empresária de moda no Brasil, refere-se ao estilo "clássico" de mulher, uma das variações que podem ser encontradas para as mulheres que assumem ou pretendem assumir a rubrica de elegantes. O detalhe principal, desse e de outros trechos muito semelhantes que podem ser encontrados nas revistas de moda, está em que, para falar sobre si mesma, a "clássica" precisa falar dos traços característicos de sua posição social, ou, mais especificamente, do conjunto de atribuições características e

${ }^{6}$ Revista VOGUE BRASIL, no 234, maio de 1997, Suplemento Especial, 3 Estilos Básicos de Mulher. 
Elegância $e$ atitude

permitidas a uma determinada situação social. Seja qual for a imagem construída, seja qual for a definição que se dê para tal mulher, fica claro que ela expressa uma dada noção de conjunto (de qualidades, atribuições e estratégias expressivas) da qual é indissociável. Há um circuito a ser seguido, espaços específicos que devem ser ocupados. O estilo a que o texto faz referência é, portanto, o indicativo da pertença a esse conjunto. Quando o conjunto ou o contexto social de referência muda, mudam também os estilos: moderno, arrojado, sóbrio, etc. Mas, apesar de haver mudanças, o sentido permanece o mesmo: declarar que aquela mulher é parte indissociável de um contexto social. No caso, privilegiado.

O detalhe mais importante de todos é que o indivíduo nunca fala de si, mas do contexto social a que pertence. A descrição do indivíduo é a descrição de seu ambiente social. Ou seja, o discurso, tanto quanto a roupa ou o próprio indivíduo, traduz sempre um ato de remissão a uma determinada concepção de ordem social, e é sempre a ela que se faz referência, é sempre ela que orienta não apenas a forma de pensar o mundo, mas também a forma de pensar a si próprio dentro desse mundo. Vejamos um outro exemplo:

É fundamental pensar nas pessoas que iremos encontrar ao longo do dia, na hora da escolha da roupa. Muitas vezes, saindo correndo de casa, só o que orienta esta decisão são as condições de temperatura e pressão - da cidade em geral e nossas em particular.

(...) Mas vale considerar, e muito, as pessoas com quem estaremos nas mais diversas situações e compromissos. Hoje é dia daquela reunião de pais na escola? Ou você vai se encontrar com os futuros patrocinadores do seu projeto de eventos culturais?

Nossa imagem precisa funcionar, precisa estar adequada.

Roupas, acessórios, postura, maquiagem: ajudam muito. 
Alexandre Bergamo

Você mostra o cuidado e respeito que teve com o outro, $e$ que naturalmente tem com você mesma. ${ }^{7}$

Embora todo o discurso seja orientado para que um indivíduo tenha estilo, ou seja elegante, o universo social não é constituído por indivíduos, mas por posições sociais e por relações entre tais posições. A etiqueta esperada nada mais é senão o cumprimento da ordem social: a discriminação e a manutenção da posição que as pessoas ocupam dentro dessa ordem. As relações entre as pessoas são sempre, com isso, relações entre posições sociais reguladas pela conveniência exigida para a manutenção dessas posições e, portanto, dessa ordem:

A menos que você more numa casinha no alto da serra, $e$ vá só até a caixa postal para pegar o jornal, alguém vai ver. Muitos verão você - o porteiro, vizinhos, moradores do bairro. Nesses dias, aliás, é infalível: encontraremos um exnamorado, uma amiga dos velhos tempos, e não é que seu colega de trabalho estava no supermercado?

Evite, evite. Resista à tentação do conforto sobre todas as coisas. ${ }^{8}$

O trecho citado acima, retirado de uma seção do livro de Constanza Pascolato com o sugestivo título de $A$ Ditadura do Conforto, é altamente representativo da forma como o universo social é pensado, representado, e de como o indivíduo interpreta sua própria inserção e a das demais pessoas nesse universo. Porteiro, vizinhos, ex-namorado, amiga e colega de trabalho são colocados a uma mesma distância da posição social de quem fala. Não significa que não haja uma hierarquia de relações. Não é esse o ponto. O detalhe é que o discurso não estabelece, entre as pessoas, relações de aproximação que traduzam relações de intimidade. As que poderia haver, como, por exemplo, com o ex-

7 PAscolato, C. Essencial... Op. cit., p.126, grifos da autora.

8 ID., IB., p.145, grifos da autora. 
Elegância $e$ atitude

namorado ou com a amiga, são colocadas em segundo plano, $e$ em seu lugar surgem relações marcadas pela distância e pela conveniência social. O espaço privado é construído, com isso, segundo regras de apresentação públicas, o que faz com que tanto o espaço público quanto o privado sejam quase indistintos. A seção citada acima, sobre $A$ Ditadura do Conforto, encerra-se, muito coerentemente com tal visão de mundo e com a imagem que o indivíduo faz de si no mundo, da seguinte forma: "Não importa que ninguém esteja vendo, não importa: conforto não é desmazelo". 9

Esse ato de remissão à ordem, representado tanto pela roupa quanto pelo corpo, ganha, portanto, expressão também através do autocontrole que o indivíduo se sente obrigado a exercer sobre si mesmo:

Experimente fazer os gestos banais o mais cuidadosamente possível. Atender o telefone. Escovar dentes. Cortar pão, levar a xícara de café à boca. Sentar-se, levantar-se. Pegar a sacola de cima do sofá. Falar (há quem não consiga se expressar sem muitos gestos).

Enfim - todos os gestos do mundo, o mais cuidadosamente possível.

(...) Pode ser um horror também - quando a gente se dá conta da imensidão de erros do corpo. Da mão que parece meio fora do controle e nunca sabe onde se colocar, ou está sempre roubando o espaço alheio; do braço que esbarra em tudo, e é rápido demais, ou flácido, sem alegria. ${ }^{10}$

A minúcia dos gestos $e$ a escolha das roupas expressam a unidade esperada entre os comportamentos e a ordem social da qual o indivíduo faz parte. Os comportamentos, embora expressos como algo alheio que possa ser aprendido, não passam de

9 ID., IB., p.145, grifos da autora.

${ }^{10}$ ID., IB., p.35, grifos da autora. 
procedimentos de autocontrole para que o indivíduo não fira a unidade esperada entre ele e a ordem social a que pertence. Nesse sentido, é altamente expressivo disso a descrição dos gestos das mãos e dos braços que "roubam o espaço alheio" ou são "sem alegria", ou seja, sem a capacidade de expressar a unidade esperada dos comportamentos e do ambiente social.

A observação dedicada aos próprios atos e aos das demais pessoas impõe uma forma de integração social, qual uma sociologia baseada em determinismos econômicos ou culturais, baseada na suposição da unidade entre os indivíduos e suas respectivas posições sociais. Vejamos um exemplo disso:

Sabe por que me interessa a emergente? Ela criou um estilo próprio. É a mulher que gosta de se enfeitar e tem dinheiro para isso. Infelizmente peca pelo excesso - e jamais estará no padrão do chique, do elegante. Mas não deixa de ter um papel interessante no nosso universo cultural, social $e$ político.

Não acho que devemos crucificar as peruas, as emergentes $e$ afins. Sim, elas ostentam. Também costumam falar alto para atrair atenção para os seus dourados: isso é imperdoável. (...) Não se esqueça do exercício de tolerância: há peruas e peruas.

(...) Não deveríamos olhar com preconceitos, porque é assim no mundo inteiro, e sempre foi. Teoricamente as peruas são casadas com homens ricos e têm tempo de sobra para fazer suas compras. Representam o novo poder, o novo dinheiro (...).

As peruas cultivam outros desejos, suas "inovações" nada têm de vanguardismo. Mas elas têm o controle da energia do kitsch - uma energia estética e necessária à sociedade, que também faz o mundo girar. ${ }^{11}$

Em poucos momentos o termo "elegante" aparece ligado a, e condensando de forma tão plena, uma unidade esperada entre

${ }^{11}$ ID., IB., pp.192-193. 
Elegância $e$ atitude

os comportamentos e a ordem social e uma certa concepção de mundo. Aquilo que é condenável, e mesmo "imperdoável", nas emergentes é o seu "excesso". Tanto a condenação quanto o uso do termo "excesso" são indicativos da falta de unidade entre indivíduo e posição na estrutura social que supostamente marcam as "peruas". O "exercício de tolerância" cobrado não traduz uma forma de aceitação e respeito social, mas uma forma de manutenção do compromisso com a etiqueta de quem fala e da posição social que acredita representar. Observa-se, através desses pequenos detalhes, que a ordem social $e$ a ordem natural são entendidas como sinônimos. A posição social ocupada pelas pessoas é aquela que lhes cabe por um destino natural. Tanto a ordem social quanto a natural são concebidas de forma estática $e$ imutável. É no interior de uma concepção de mundo como essa que faz sentido uma formulação tal como "é assim no mundo inteiro, e sempre foi". Assim como faz sentido a suposição de que a emergente "jamais estará no padrão do chique, do elegante". As "peruas" são toleradas, portanto, não apenas como forma de exercício de etiqueta, mas também porque são interpretadas como tendo um caráter funcional ("uma energia estética e necessária à sociedade, que também faz o mundo girar") dentro da ordem social e natural, esta sim devendo ser respeitada e compreendida na sua totalidade e unidade. $\mathrm{O}$ curioso é que análises muito semelhantes a essa podem ser também encontradas em diversos trabalhos importantes que têm o kitsch ou a cultura popular como tema, indício de que seus autores compartilham concepções de mundo bastante semelhantes. É em função dessa concepção de mundo que as roupas, os gestos, o discurso, a decoração, etc. adquirem significação enquanto atos de remissão à ordem social $e$ natural.

O livro de Constanza Pascolato citado até agora ${ }^{12}$ pode ser tomado, de uma certa forma, como fazendo par com outro, o de

${ }^{12}$ ID., IB. 
Fernando de Barros. ${ }^{13}$ Tomados isoladamente ou em conjunto, eles estabelecem uma diferença fundamental: de gênero. As diferenças são marcantes não apenas porque os livros foram escritos para gêneros distintos, mas porque frisam, através das roupas, as particularidades a serem seguidas para que as diferenças de gênero fiquem constantemente marcadas. $\mathrm{O}$ fato de que os dois subtítulos sejam escritos de forma imperativa, "precisa saber" e "deve", é bastante expressivo do fato de que uma certa ordem social e natural de mundo deve ser mantida. Sendo assim, é fundamental que essa ordem não seja comprometida e que, portanto, não haja confusões entre o guarda-roupa masculino e o feminino. Ou seja, as diferenças de gênero são relevantes aqui não porque a partir delas se constitui a identidade social, mas porque demarcam posições sociais entendidas como naturais dentro de uma concepção de mundo estática $e$ imutável e que supõe uma coincidência entre a ordem natural e a social. Com isso, os livros são, essencialmente, atos de cobrança dessa suposta ordem natural e social.

A idéia de elegância, contudo, não pode ser reduzida unicamente a uma questão de visão de mundo. Ela traduz e, ao mesmo tempo, resolve conflitos sociais bastante específicos. Vejamos sob que outras formas, além do discurso de moda, esses conflitos ganham expressão. As fotos abaixo foram feitas em duas lojas, ou butiques, consideradas elegantes:

${ }^{13}$ Barros, F. de. Elegância... Op. cit. 




Figura 1

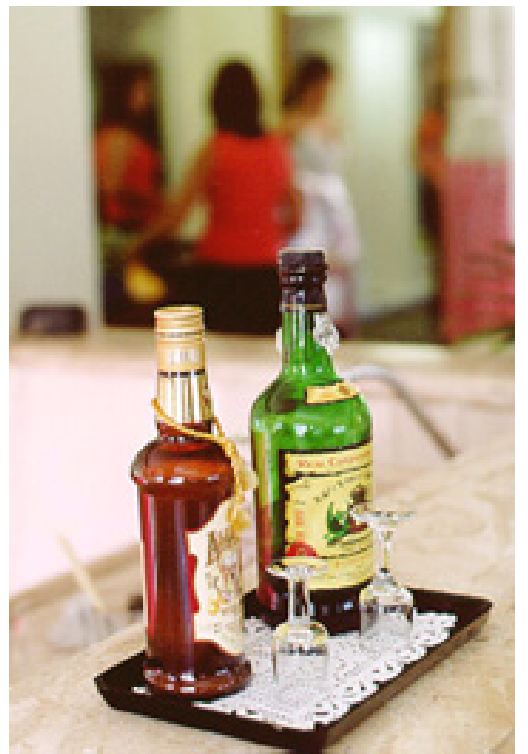

Figura 2

Tanto o espaço quanto a decoração apresentam características em comum. O espaço é amplo, permite o movimento $e$ a prova de roupas, como pode ser observado na segunda imagem, em segundo plano, mas a característica principal desses ambientes está no fato de que a roupa é um dos traços expressivos de um conjunto maior de atribuições. Assim como o discurso de moda, a roupa, a decoração ou a música, que muitas vezes aparece de fundo em tais lojas, são possibilidades expressivas que permitem que o indivíduo seja inserido no interior de um conjunto de atribuições. Assim, cada um desses elementos, inclusive o indivíduo, é sempre remetido a um conjunto maior e que é expressivo de uma determinada ordem estética.

A ordem estética representa, contudo, também uma discriminação da ordem social. O espaço é utilizado de tal forma que passa a adquirir importância social: ele expressa, e espera, uma sociabilidade entre as pessoas. Mas, evidentemente, apenas 
Alexandre Bergamo

entre determinadas pessoas. Nesses ambientes, as pessoas geralmente se conhecem e conversam sobre os lugares em comum que freqüentam: festas, clubes, recepções, casas de amigos, etc.

Observa-se também uma integração entre as cores das roupas e os elementos de decoração. A imagem veiculada no interior da loja nunca é a da peça por si só, mas do conjunto. Observa-se também o uso de elementos que indicam uma posição social privilegiada: móveis, bebidas, obras de arte, antiguidades, etc., sendo que o gozo desses elementos é uma prerrogativa da posição social ocupada pelos freqüentadores dessas lojas.

As vitrines são menos exploradas, de forma a que o interior da loja fique visível para quem está passando pela frente. A primeira das fotos, por exemplo, foi feita do exterior da loja, através da vitrine. Há a nítida intenção de visibilidade do interior da loja e de quem ali se encontra, ela exerce o papel de fronteira entre dois ambientes, entre um público e um privado. Embora o espaço privado precise ser pautado nas mesmas regras que se compõe o espaço público, como pôde ser visto claramente nos trechos de moda discutidos anteriormente, a diferença visível entre público e privado traduz diferenças e distâncias sociais significativas. Por vezes não há vitrines, pois algumas das casas onde estão situados estes estabelecimentos comerciais não possuem algo que possa ser utilizado como tal, fazendo com que seu interior fique oculto a quem passa por fora. Ocorre uma filtragem do olhar que pode ou não alcançar o interior dessa loja, independentemente de este ser resultado de algum propósito claro e pré-definido ou não. Assim, a roupa, a decoração, a vitrine, a utilização do espaço, etc. são elementos que permitem a demarcação de fronteiras, permitem que a distância entre esse indivíduo e os demais grupos sociais fique assim sublinhada. Ou seja, permitem frisar a distância social entre seu usuário $e$ os demais.

Se tomarmos o discurso anterior e compararmos com as demarcações observadas nos espaços das lojas, parece que estamos diante de um descompasso. Isso porque o discurso de 
Elegância $e$ atitude

moda citado anteriormente utiliza uma linguagem indiferenciada $e$ supostamente destinada a qualquer indivíduo de forma indistinta, independente de classe ou grupo social, estabelecendo apenas uma única e clara distinção entre as pessoas, a de gênero. Contudo, o discurso não pode ser entendido como isento de uma conotação social e como alheio a uma série de conflitos sociais. Embora a linguagem não faça distinções de classe, ela é construída de forma a condenar aqueles que invadem, como as emergentes, o que é considerado seu espaço de direito e de pertença. Ainda que a presença de pessoas de classes diferentes seja visível, como empregados, os indivíduos falam de si e do mundo a que pertencem como se fosse composto por uma única classe, a sua. É a ela que se refere a concepção de ordem expressa. Os demais grupos tendem a ser vistos como desvio, como no caso das emergentes, ou como desprovidos das qualidades naturais que tornam a classe descrita - privilegiada - a referência para os comportamentos. O discurso, a roupa e a decoração remetem, com isso, não apenas a uma dada concepção de ordem social e natural, mas também a uma ordem de privilégios. O que explica o fato de que muitas vezes o termo "elegância" seja acompanhado ou mesmo substituído pelo termo "classe". Não se trata, portanto, de uma ordem social e natural indiferenciada em termos de classe. Ao contrário, refere-se especificamente a uma situação de classe no interior da ordem social.

Tive a oportunidade e a gentileza de ser recebido por Dona Gabriela Pascolato, proprietária de uma das mais tradicionais e importantes tecelagens do Brasil e mãe da bastante citada aqui Constanza Pascolato, em seu apartamento em Higienópolis, São Paulo. Fui acompanhado por Carlos Mauro Fonseca Rosas, responsável por mais de uma década pelo setor de moda da Rhodia S.A., cuja amizade e presença foram muito importantes em vários momentos de minha pesquisa. A visita havia sido marcada para que eu tivesse a oportunidade de ver o arquivo pessoal de fotos de Dona Gabriela e escolhesse algumas das imagens para 
Alexandre Bergamo

serem escaneadas. Contudo, o que mais me chamou a atenção nessa visita não foi seu arquivo de fotos, mas a paisagem de sua janela. De sua janela vários edifícios podiam ser observados. $\mathrm{O}$ que ela nos mostrou, no entanto, era algo que eu só poderia ver através de seus olhos. Ela apontava os prédios e dizia:

aquele prédio é importante, ali mora o Fulano de Tal. Aquele outro não é, ali não mora ninguém importante. Aquele outro é importante também, ali mora Sicrano de Tal.

E assim foi, um a um, indicando os prédios. Onde eu via edifícios, ela via uma complexa topografia de posições de prestígio na ordem social. O que movia seu olhar não era uma motivação política, moral ou ética. A motivação era simplesmente a demarcação espacial de uma ordem de mundo entendida como sinônimo de prestígio e confundida com uma ordem natural. Era também, principalmente, a demarcação da sua posição no interior dessa ordem. Assim, a representação de mundo se confunde com a auto-representação no mundo.

Dona Gabriela permitiu também que eu fizesse um retrato seu. $\mathrm{O}$ queixo erguido e a mão cuidadosamente disposta diante do corpo num gesto sutil e discreto traduzem a altivez da imagem que faz de si. O que deve ser entendido como a altivez que faz da imagem de seu próprio ambiente social. A minúcia dos gestos, a postura do queixo e do corpo e a escolha do ambiente expressam a unidade esperada entre os comportamentos e a ordem social da qual o indivíduo faz parte. A imagem acabou resultando um duplo. Impensável sem fazer referência ao ambiente social do qual faz parte, Dona Gabriela, em primeiro plano, torna-se, de certa forma, um duplo de sua existência social ao assumir a postura de um duplo da imagem que está em segundo plano e que compóe, entre tantas outras imagens espalhadas por seu apartamento, sua referência de mundo. 
Elegância e atitude

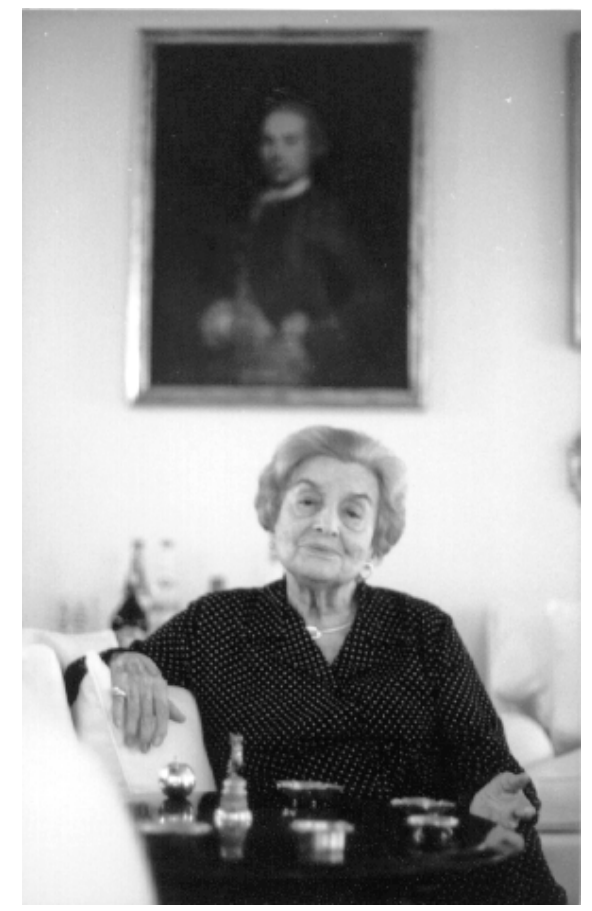

Figura 3 - Gabriela Pascolato

Atitude

Certas formas de relação com a moda não ganham expressão através de manuais. Estes estão restritos a duas concepções de mundo que se organizam e expressam através das idéias de elegância e inteligência. ${ }^{14} \mathrm{~A}$ autoridade de que se revestem tais idéias é indicativa de que elas traduzem uma disputa pelo poder tanto no mercado de moda quanto no seu respectivo mercado editorial. $\mathrm{O}$ fato de que tais idéias possam ser tomadas como opostas dentro desse contexto deve ser tomado como

\footnotetext{
${ }^{14} \mathrm{~A}$ idéia de inteligência associada ao bom gosto e à moda não será discutida aqui. A ela estão associadas mudanças sociais significativas que, por isso mesmo, mereceriam um tratamento à parte.
} 
indicativo de que tais concepções de mundo, assim como as formas de realização econômica e estética que elas traduzem, são inconciliáveis.

Além dessas formas de relação com a moda que disputam entre si o poder e o controle do mercado editorial, há uma outra forma específica de relação com a moda que está excluída dessa disputa pelo poder, e que, portanto, está excluída do mercado editorial especializado e entendido como legítimo. Em função disso, só se pode chegar até ela através de fontes bastante diversas, como publicações não consagradas ou formas de manifestação e de mecanismos de expressão específicos, não legítimos ou mesmo marginais.

Novelas, revistas semanais de fofocas, varejões de roupas, camelódromos, pagode, rap, funk, etc. compõem o universo do chamado "gosto popular" e evidenciam o desprezo de uma elite cultural e de um corpo de profissionais autorizado e legítimo sobre moda. Esse gosto não é geralmente reconhecido pelos meios de informação consagrados do mundo da moda, que se esforçam diariamente para esvaziar de sentido tais manifestações. Uma das formas mais usuais de esvaziamento de sentido das manifestações populares é sua classificação como sendo uma forma de imitação, como o exemplo abaixo:

VISUAL COPIADO

Atrizes ditam a moda nos salões e obrigam cabeleireiros a ver novelas

Janete Trevisani

A tevê se transforma em passarela. É o cabelo da Glória Pires, as estampas da sem-terra Luana (Patrícia Pillar) [na novela $O$ Rei do gado], as mechas de Camila Pitanga em Malhação, as saias curtas de Magda (Marisa Orth) em Sai de Baixo... A telinha dita a moda, muitas vezes de forma elegante, outras com pitadas exageradas de mau gosto.

O corte de cabelo de Cláudia Alencar em Anjo de Mim mostra a antitendência, mesmo assim tem telespectadora com a revista noveleira da semana na mão para mostrar ao 
Elegância $e$ atitude

cabeleireiro de confiança, louca para copiar o modelinho, $e$ haja argumento para convencê-la de que o corte não é o ideal para o seu rosto e personalidade. (...)

\section{CORTES DA TELINHA}

Clientes desprezam revistas especializadas e optam pelo que a tevê exibe

(...) É comum as clientes chegarem ao salão com uma revista nas mãos para apontar o corte de alguma atriz, outras vezes apenas citam o corte e o cabeleireiro precisa estar antenado com as novidades mostradas na telinha. $(\ldots)^{15}$

O uso que se observa, nos veículos especializados $e$ legítimos de moda, da expressão "gosto popular" deixa patente seu não-reconhecimento e uma homogeneização de diferenças para as quais não se reconhece nenhum estatuto. Ignoram-se as formas possíveis de relação das pessoas com tais manifestações expressivas, as possibilidades de significados sociais, políticos, culturais ou morais que possam ter. Em seu lugar, a idéia mais divulgada é de que se está diante de um consumo caracterizado como inerte ou irrefletido, o que fica, no exemplo citado acima, claramente indicado através de expressões como "haja argumento para convencê-la de que o corte não é o ideal para o seu rosto e personalidade". Outro reforço dado a esse esvaziamento de sentido é o caráter bizarro das notícias veiculadas e a suposta "ausência de medida" associada ao gosto popular, como também se pode observar na matéria citada ao fazer referência às "pitadas exageradas de mau gosto". Tais manifestações adquirem um caráter bizarro e de ausência de medida não porque assim o são, mas porque assim é a linguagem utilizada - e considerada legítima - pela imprensa para sua descrição.

Contudo, há um sentido particular sendo expresso em todas essas manifestações. O principal termo utilizado para designar esse

${ }^{15}$ Correio TV, Jornal Correio Popular, Campinas - SP, 21-09-96. 
Alexandre Bergamo

sentido é atitude. O exemplo abaixo traduz de maneira ímpar essa forma de expressão que não encontra sua possibilidade de realização nos manuais de moda, embora a encontre na música $e$ através de uma forma particular do consumo de moda:

HÓSPEDE DO TEMPO

Sou hóspede do tempo

Da minha casa

Das minhas palavras

Das coisas que declaro minhas

Inquilina da vida que me foi dada

Portanto, nada

Ficou na minha bagagem

Do velho brinquedo

Que já não ilude, não me ilude

O que eu tenho é minha atitude

O que eu levo é minha atitude

O que pesa é minha atitude

Minha porção maior

(Fred Martins / Zélia Duncan)

A realidade não é concebida como se o indivíduo fosse parte indissociável de um determinado contexto social. Ao contrário, a realidade, concebida a partir de uma perspectiva individualista, é descrita como se ela se estruturasse unicamente a partir da ação ou da expressão individual. Não é o ambiente social que imprime um sentido ao indivíduo, mas o indivíduo que imprime um sentido a sua inserção social, ainda que eventual ou momentânea. A idéia de atitude não cobra, necessariamente, uma ordem social e natural, mas uma ordem pessoal. $\mathrm{O}$ uso do termo expressa uma concepção de mundo composta por indivíduos isolados, e não por grupos ou classes sociais, ainda que eles existam e que se lhes possa fazer referência. Observa-se, ao contrário da idéia de elegância, uma rejeição do ambiente social de pertencimento ("Inquilina da vida que me foi dada / Portanto, nada / Ficou na minha bagagem"). O universo social do qual o 
Elegância $e$ atitude

indivíduo faz parte só é requisitado para realçar as qualidades pessoais, ainda que elas não ganhem uma definição clara. A principal característica da idéia de atitude, dentro desse contexto, é que ela representa uma interpretação de mundo que consiste da expressão de impressões individuais. Impressões individuais $e$ consciência coincidem e representam um mundo em que as relações são sempre estabelecidas com base no tempo presente ("hóspede do tempo"), o que faz com que a idéia de atitude seja bastante fluida. $\mathrm{O}$ caráter individualista ganha expressão através de uma linguagem que não estabelece outras relações senão com virtudes e paixões que, ainda que não tenham sido nomeadas no exemplo citado, são entendidas e expressas como qualidades $e$ disposições individuais, pois traduzem a coincidência entre consciência e impressões subjetivas. O discurso consiste, portanto, de um ato de remissão a essa consciência que ganha forma através de virtudes e paixões entendidas como expressões individuais.

Esse é o mesmo sentido expresso por alguns gerentes, vendedores e consumidores do circuito mais popular do varejo de moda, mas também por drag queens, clubbers, descolados ou mesmo iniciados no mundo da moda, também freqüentadores desse circuito popular em busca de produtos de moda originais. $\mathrm{O}$ termo, contudo, nunca é utilizado para descrever tais lojas, mas sim as próprias pessoas que falam. Esse comércio das classes baixas apresenta características particulares, diferentes daquelas que podem ser observadas nas lojas de roupas de luxo: 
Alexandre Bergamo

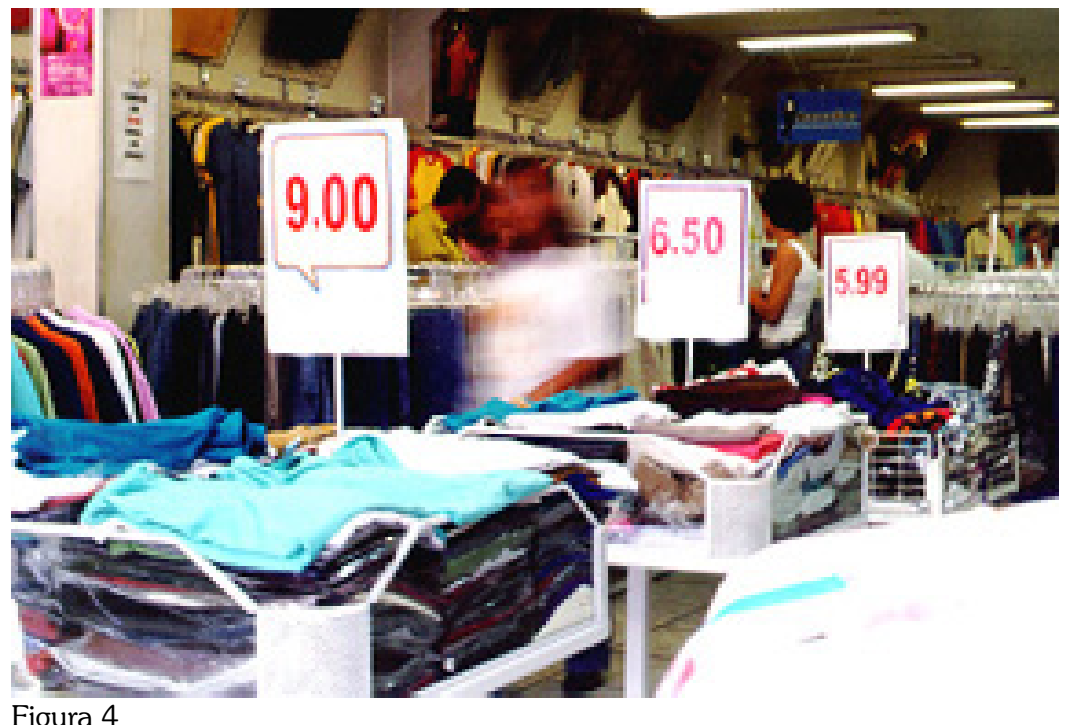

Figura 4

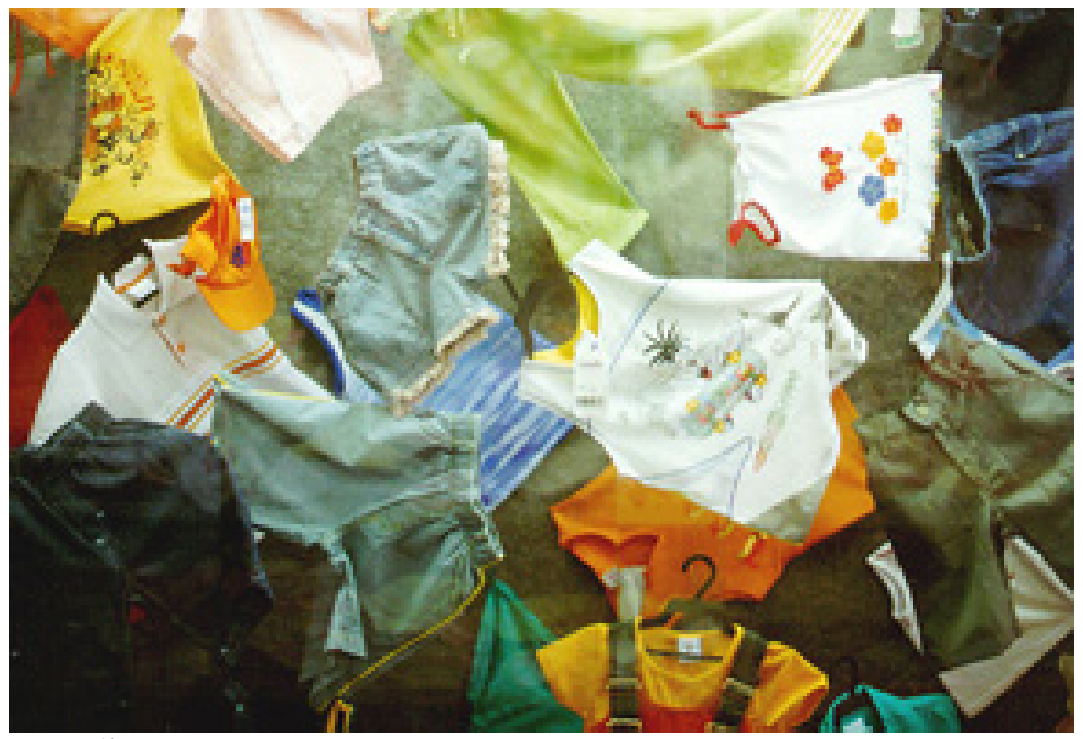

Figura 5 
Elegância $e$ atitude

A principal característica dos muitos varejões espalhados pela cidade é o preço, geralmente baixo, e que, aparentemente, organiza a distribuição de produtos pelo espaço no interior das lojas, como no caso da primeira imagem. A explicação de senso comum para essa evidência tão marcante dos preços baseia-se numa racionalidade de caráter utilitário fundada nas diferenças de poder aquisitivo entre os grupos e as classes sociais: o preço tornase fator de preocupação e distinção quanto mais baixa é a posição na estrutura social. $\mathrm{O}$ baixo poder aquisitivo justificaria, para essa mentalidade de senso comum, um consumo parcial: uma vez que não é possível dispor de dinheiro suficiente para a compra de todas as peças de um conjunto, como calça, camisa e sapatos combinando, a aquisição se restringe a peças isoladas que têm como fator de escolha seu preço. Além da idéia de um consumo parcial, aqui se vê repetida uma outra, que marca a imagem que a imprensa especializada faz do consumo das classes baixas, a de imitação. O consumo das classes baixas é quase sempre classificado como orbitando o consumo das elites, obviamente desprovida de critérios próprios de gosto.

Mas talvez a lógica não seja exatamente essa. Quando se observa com atenção o interior dessas lojas, pode-se ver que o seu espaço é restrito, é o suficiente para o trânsito das pessoas, ele é preenchido inteiramente pelas peças de roupas. O espaço não é, ao contrário das lojas de luxo, constituído para ser um espaço de sociabilidade, apenas de trabalho, para os funcionários, e de consumo. O espaço, portanto, não tem relevância enquanto fator de expressão do gosto.

No caso da decoração, observa-se que a roupa não é integrada a nenhum ambiente específico. Outra característica que chama bastante a atenção é a disposição aleatória de peças, como no caso da vitrine retratada na Figura 2. A ausência de uma disposição que siga uma ordem de conjunto, onde a peça de roupa é remetida a um dado contexto ou a um determinado estilo onde roupa, decoração e indivíduos expressem uma noção de conjunto, não significa, como pode parecer para muitos, ausência 
de lógica. Há, ao contrário, uma lógica específica sendo expressa. Portanto, assim como o espaço, a decoração, no caso dessas lojas, também não tem nenhuma relevância enquanto fator de expressão do gosto.

Diferentemente das lojas de luxo e de vitrines, vistas anteriormente, aqui a ênfase não recai sobre um conjunto de peças integradas, mas sobre a própria peça em si. A peça de roupa, por si só, e não um ou mais conjuntos determinados, agrega um valor simbólico específico. Há, portanto, um sentido determinado que atribui um valor simbólico específico para as peças de roupa isoladamente.

Esse sentido está ligado, em primeiro lugar, ao fato de que a posição na estrutura social é, para a maioria esmagadora dessas pessoas, uma contingência. Ao contrário das elegantes, que celebram seu prestígio e seu ambiente social, não há aqui porque celebrar a pressão social sofrida. Celebra-se, ao contrário, tudo aquilo que possa se sobressair a essa pressão, tudo aquilo que possa dissimular uma identidade que nada mais seria senão o resultado de uma contingência, o resultado da exclusão dos meios por excelência de promoção social.

$\mathrm{E}$, em segundo lugar, ao fato de que a interpretação de mundo se faz de uma perspectiva individualista. As relações com a roupa são estabelecidas a partir das impressões e disposições individuais. A idéia de conjunto não é, portanto, estabelecida exteriormente ao indivíduo. O próprio indivíduo, e apenas ele, representa um conjunto por si próprio. Não é no espaço da loja que o indivíduo encontra sua dimensão expressiva, mas em si mesmo. A não ser, é claro, que a intenção expressiva seja outra, como, por exemplo, dar provas da ascensão social.

Pode-se observar, nas publicações direcionadas para o chamado gosto popular, essas mesmas características que lhe são próprias e que lhe conferem sentido, como no exemplo abaixo: 
Elegância $e$ atitude

\section{INDOMADAS \& PODEROSAS}

Para ser a estrela da festa, a recatada noiva Doroty (Flávia Alessandra) entrou num processo de transformação $e$ ganhou ares de felina com o modelo 558, um longo godê de cetim e veludo, com decote frente-única.

A força e a beleza de Helena (Adriana Esteves) se traduzem no imponente modelo 556, que aparece na capa desta edição. No melhor estilo império, ele reforça a personalidade marcante de quem o veste (...)

Santinha (Eliane Giardini) é uma mulher sensível, frágil, mas não passa despercebida. Aqui, a proposta é evidenciar sua delicada sensualidade (...)

Impetuosa, Scarlet (personagem de Luíza Tomé) não mede esforços para ser o centro das atenções da festa da irmã. Tanto que abusa da fenda que deixa à mostra suas pernas bem torneadas $(. . .)^{16}$

A revista de onde foi retirado o trecho acima não figura, como referência de moda, entre aquelas consideradas consagradas. Trata-se de uma publicação direcionada para a população de baixa renda, que supostamente precisa "copiar" os modelos utilizados pela televisão, considerada, esta sim, como sua principal referência de moda. A característica principal que se pode observar é que a ênfase da descrição recai no indivíduo de uma forma bastante particular. Diferentemente do que foi visto no caso da idéia de elegância, para falar dos indivíduos, personagens de novela ou não, não se fala do ambiente social ao qual pertencem. $\mathrm{O}$ discurso assume um caráter extremamente personalista. $\mathrm{O}$ individualismo marca a descrição do indivíduo $e$ de sua roupa de tal forma que ambos são descritos através de termos que se complementam no seu sentido personalista. Assim, a roupa imponente da atriz traduz sua personalidade marcante, a delicada sensualidade de outra roupa traduz uma mulher sensível e frágil, em outra, ainda, a fenda traduz o caráter impetuoso da

${ }^{16}$ Revista Manequim, ano $38, n^{\circ} 08$, agosto/97, grifos meus. 
personagem. A descrição é feita de uma tal maneira também que as características associadas ao corpo são tomadas como qualidades naturais e indissociáveis do indivíduo.

Uma vez que as roupas são entendidas como expressões individuais, os termos utilizados para elas, assim como para os cortes de cabelo, são, muitas vezes, os mesmos utilizados para os indivíduos e suas qualidades. Com isso, as roupas, ou, mais especificamente, as peças de roupa, podem ser: iradas, insanas, nervosas, poderosas, sensuais, românticas, sonhadoras, "maneiras", legais, "do bem", etc. Cada uma dessas peças de roupa coincide com a qualidade de quem as usa e traduz a sua atitude diante do mundo e diante da moda.

Essa forma de interpretação do mundo e da posição ocupada nele não está, obviamente, desprovida de marcas de gênero e sociais. Contudo, é o caráter individualista da interpretação que confere significação a tais marcas. As marcas de gênero, em diversos momentos, deixam de ter relevância. A idéia de que a roupa traduz uma determinada qualidade encontra expressão através de um visual que, em várias situações, homogeneíza homens e mulheres através de roupas muito semelhantes. O detalhe interessante é que, embora algumas formas de expressão estéticas sejam exclusivamente masculinas ou femininas, o discurso é, na maior parte das vezes, estruturado como se não tivesse gênero. Não porque a diferença entre os gêneros não exista, mas porque as distinções se estruturam a partir das diferenças entre virtudes humanas.

Esse mesmo sentido pode estruturar o discurso do conflito social ou político, como se observa no exemplo abaixo:

\section{Capítulo 4 Versículo 3}

$60 \%$ dos jovens de periferia sem antecedentes criminais já sofreram violência policial a cada quatro pessoas mortas pela polícia, três são negras nas universidades brasileiras, apenas $2 \%$ dos alunos são negros 
Elegância $e$ atitude

a cada quatro horas um jovem negro morre violentamente em São Paulo

aqui quem fala é o Primo Preto, mais um sobrevivente

(...)

Eu tenho uma missão e não vou parar!

Meu estilo é pesado e faz tremer o chão!

Minha palavra vale um tiro, eu tenho muita munição!

Na quieta ou na ascensão, minha atitude vai além!

(...)

Vim pra sabotar seu raciocínio!

Vim pra abalar o seu sistema nervoso e sanguíneo!

(...)

Permaneço vivo, prossigo a mística!

27 anos, contrariando a estatística!

Seu comercial de TV não me engana

Hã! Eu não preciso de status nem fama

(Mano Brown)

As marcas sociais são expressas em seu sentido individualista. O trecho acima foi retirado de um rap, movimento que ganha expressão através da música, da moda, da afirmação de virtudes humanas independente do seu contexto social de origem, pobre, e da crítica àqueles que não têm a mesma origem - postura que cai num determinismo semelhante ao expresso pela idéia de elegância - ou a mesma atitude através de uma linguagem agressiva, de enfrentamento da ordem social ("Vim pra sabotar seu raciocínio! / Vim pra abalar o seu sistema nervoso e sanguíneo!"). A idéia de afirmação social e política se confunde com a idéia de afirmação individual através da rejeição da ordem social.

A linguagem expressa, mais uma vez, uma concepção da realidade extremamente subjetiva, onde as trajetórias pessoais são vistas como fruto da ação do indivíduo, e um caráter eminentemente moral, onde os sucessos e os fracassos são vistos como conseqüencias apenas da ação individual. Mas o detalhe mais significativo é que o indivíduo é colocado de forma a exibir 
Alexandre Bergamo

sempre o mesmo conflito: entre o homem, de um lado, e o destino, de outro. As forças contra as quais o indivíduo luta não são sociais. A força contra a qual o indivíduo luta é de outra ordem: o destino ("Permaneço vivo, prossigo a mística! / 27 anos, contrariando a estatística!").

Através da novela, da música, da moda um indivíduo pode fazer-se expressivo, pela sua influência, sobre um grande número de pessoas independente da classe social. Ou seja, os indivíduos são convocados, da vulgar quotidianidade de suas vidas, para desempenharem os mais portentosos papéis ("Eu tenho uma missão e não vou parar! / Meu estilo é pesado e faz tremer o chão!"). Cada indivíduo representa, nesse contexto, um exemplo para as demais pessoas. E, assim, os sucessos vulgares do dia alcançam uma significação maior.

\section{Marcas e sentidos sociais}

A questão colocada logo ao início deste texto, sobre as diferenças de gênero e seu papel na produção e no consumo de moda, talvez precise ser refeita. Em seu lugar talvez seja mais pertinente indagar sobre o que confere significação à produção, ao consumo, aos indivíduos e, mesmo, ao gênero no mercado de moda.

As formas possíveis de ligação entre o indivíduo e a moda correspondem às formas possíveis de ligação entre o indivíduo $e$ a sociedade. Ou seja, através da moda pode-se ver como o indivíduo pensa a si próprio e sua inserção no tecido social. A moda não é, em hipótese alguma, determinante das formas de pensar. As diferenças que podem ser observadas no mercado de moda são as mesmas observadas nas pessoas em seu cotidiano. A moda é, antes de mais nada, um instrumento de realização e de atualização das diferentes possibilidades de inserção das pessoas no jogo social. Seu limite e sua significação estão, portanto, nesse jogo social. 
Elegância $e$ atitude

Além disso, esses conflitos sociais não são vividos pelos indivíduos de uma forma tão típico-ideal quanto a apresentada aqui. Embora toda a discussão tenha sido centrada no uso de dois termos, e nas oposições que podem ser observadas através dos sentidos que eles expressam, é importante lembrar que esses sentidos não são unívocos, o que dificulta, em vários momentos, a análise. Vejamos um exemplo disso ligado à idéia de atitude:

Por favor, não confunda atitude com arrogância: não há nada mais fora de moda e sem estilo. Atitude tem a ver com valorização pessoal, com o desejo e a capacidade de fazer o máximo que você tem. É um investimento. Faça-o por você, porque precisa $-e$, sobretudo, merece. ${ }^{17}$

Tomado assim, isoladamente, esse trecho indica que se está diante de uma linguagem estruturada com base em seu caráter individualista. É isso que sugerem as idéias principais: de "valorização pessoal", "o desejo e a capacidade de fazer o máximo que você tem" e a idéia de que isso é feito em nome do próprio indivíduo. Contudo, a continuação do trecho citado sugere outra coisa:

Faça pelos outros. Com charme. No mínimo vai ser questão de respeito e delicadeza com os lugares que freqüenta, as pessoas que conhece, o trabalho que faz. ${ }^{18}$

O sentido passa a ser outro. O triunfo do indivíduo passa a ser sua capacidade de auto-controle $e^{19} e$ de adequação a um determinado ambiente social. A "arrogância" a que a citação faz

${ }^{17}$ Pascolato, C. Essencial... Op. cit., p.15.

18 ID., IB.

${ }^{19}$ Sobre a questão do auto-controle, ver EliAS, Norbert. El Proceso de la Civiliztión: investigaciones sociogenéticas y psicogenéticas. México, D. F., Fondo de Cultura Econômica, 1989, 2a . Ed.; e EliAS, Norbert. A Sociedade de Corte. Lisboa, Estampa, 1995. 
Alexandre Bergamo

referência logo no início consiste, portanto, no perigo de que a individualidade seja marcada de tal forma a se sobressair ao ambiente social. Evidentemente, o ambiente social a que o trecho faz referência é aquele de pertencimento de quem fala. Ainda assim, a linguagem é estruturada com base no seu caráter individualista.

Já em outro exemplo citado anteriormente, das "Indomadas \& Poderosas", embora todo o discurso se estruture com base no individualismo, ele surge no interior de uma concepção de mundo baseada numa ordem estática e imutável entendida como uma ordem natural. Com isso, os termos utilizados para designar as personagens de novela, tanto quanto as roupas descritas, expressam qualidades e mecanismos de expressão entendidos como "naturalmente femininos". E assim o discurso individualista da "atitude", que em vários momentos estrutura-se através de uma linguagem sem gênero, ganha força exatamente pela expressão das diferenças de gênero, entendidas como diferenças naturais.

O que se observa, através desses exemplos, é que não apenas esses termos não apresentam um sentido unívoco como também podem condensar sentidos muito diferentes $e$, até mesmo, inconciliáveis. A depender do contexto e de quem fala, tanto a idéia de atitude quanto a de elegância podem querer caracterizar, ao mesmo tempo, marcas individuais, culturais, sociais e de gênero. O que, portanto, afasta qualquer análise de caráter determinista que suponha que elegância e atitude sejam tão somente marcas de classe que oponham, de um lado, elite e, de outro, classes baixas, ou mesmo qualquer determinismo cultural que se baseie em oposições simbólicas, uma vez que os termos traduzem, muitas vezes, visões de mundo.

$O$ fato de que esse conflito ganhe forma através da expressão de diferentes maneiras de pensar a inserção do indivíduo no jogo social é indicativo de que ele traduz não visões de mundo, no sentido culturalista que a expressão possa ter, mas sim experiências de mundo diferentes e que não podem ser 
Elegância $e$ atitude

reduzidas à homogeneidade cultural ou à univocidade simbólica, experiências que oscilam entre o compromisso com a ordem social estabelecida e a exclusão dos mecanismos legítimos de reconhecimento e promoção social. Mas não apenas isso. É como se, aos indivíduos, fosse vedada a possibilidade de ocupar um ou outro extremo dessa oposição, restando a eles a possibilidade de ocuparem apenas o seu interior, ora expressando mais um sentido, ora outro, ora tentando realizar a impossível tarefa de conciliar sentidos inconciliáveis. A impossibilidade de ocupar um ou outro extremo da relação reside no fato de que, num mundo concebido como estático e imutável, as oscilações ou ameaças são sempre interpretadas como resultado de acidente, sorte ou ação deliberada de outrem. O individualismo que surge é, portanto, parte inseparável dessa concepção de mundo ${ }^{20}$, e pode ou ser interpretado como um acidente que deva ser creditado à ação de alguém, como no caso da "arrogância" a que a citação mais acima fez referência, ou enaltecer, e mesmo exagerar, traços entendidos como naturais, como no caso das "Indomadas \& Poderosas", ou fortalecer o contraste com a ordem natural, como no caso do rap citado. Nesse contexto, o indivíduo nunca combate forças sociais, mas forças naturais, entendidas como o destino. E quanto mais forte é o caráter individualista do discurso, mais ele ganha um caráter moral ou alegórico ${ }^{21}$ através de uma linguagem, de roupas e de comportamentos que expressam ora uma instituição, como a família ou a justiça, ora uma virtude, como a sabedoria ou a força, ora uma paixão, como o desejo, ou então várias dessas características ao mesmo tempo.

A fluidez na significação e o fato de que os diversos sentidos possam aparecer condensados em vários momentos indicam que a linguagem, a roupa e os comportamentos não podem ser

${ }^{20}$ Sobre as origens e transformações do individualismo, ver AUERBACH, Erich. Mimesis. São Paulo, Perspectiva, 1998, 4a . ed.

${ }^{21}$ Sobre a representação alegórica da realidade, ver ID. Figura. São Paulo, Ática, 1997. 
tomados, uma vez que apontam para uma dimensão expressiva, simplesmente como duplicatas simbólicas do jogo social. A significação da produção, do consumo $e$, mesmo, do gênero no mercado de moda reside, portanto, no fato de que através da linguagem, das roupas e dos comportamentos provam-se - e, principalmente, estabelecem-se as conexões entre - uma dada forma de representação da realidade, de representação do indivíduo em seu interior e de experiência social efetiva, de compromisso com a ordem social ou de exclusão. 